Letter to the Editor

\title{
Nurse residency program: a promising, yet neglected strategy for the education of senior nursing students
}

\author{
Hossein Karimi Moonaghi ${ }^{1,2}$, Hassan Sharifi ${ }^{3 *}$, Amir Emami Zeydi ${ }^{4}$, Mohammad Reza Armat ${ }^{5}$
}

(Received: 6 Sep 2016; Accepted: 30 Oct 2016)

Quality and safety of patient care remarkably depend on the competency of healthcare providers. As predominant caregivers, nurses crucially influence the quality of patient care (1). On the other hand, as major educational organizations, nursing schools must offer competent expertise to the students in order to warrant high-quality patient care. In this regard, finding efficient methods to graduate competent and confident nursing professionals is a major challenge in these organizations (2).

To accomplish this, nursing faculty members adopt a variety of clinical instructional strategies in order to increase the quality of educational programs, which ultimately enhances the quality of patient care. Nevertheless, the literature is suggestive of the failure of current strategies to achieve the expected level of competency in senior nursing students as an important influential factor for patient care (3). In other words, strategies adopted in the $20^{\text {th }}$ century can no longer be applied in the $21^{\text {st }}$ century.

To overcome this limitation, nursing schools have incorporated practical courses into their curricula of the Bachelor of Science Degree. These courses are typically known as "transition" or "capstone", which are presented as the last course for the Bachelor of Science in Nursing, so that students could work one-on-one with an individual preceptor in the clinical setting.

However, this strategy is difficult to apply since it requires highly qualified instructors, increases the workload of nurses, and demands adequate resources. Literature review indicates that the transition of baccalaureate nursing graduates from the academic environment to the professional workforce is a major educational challenge (4).

Currently, it is believed that the expected quality of patient care is not achieved by the competency of newly graduated nurses. Therefore, many healthcare agencies conduct "residency programs" or "registered nurse internship programs" in order to enhance the competency level of newly graduated nursing staff.

In general, a nursing residency program consists of classroom instructions, manuals of skills and tasks, an orientation period, and professional and organizational support (3). Several studies have denoted the pivotal role of the nursing residency program in the preparation of competent nurses for professional performance in the clinical setting, reducing employee turnover and theory-practice gap, and increasing job satisfaction, retention, commitment, and patient care quality $(1,3)$. Despite the established benefits of the nursing residency program in hospital settings, data is scarce regarding its potential effects on the educational program of baccalaureate nursing students.

Considering that current clinical courses have failed to enhance the competency of senior nursing students (2), nursing school educators must shift their attention from routine clinical education to creative and effective programs, such as the nursing residency program. It

\footnotetext{
${ }^{1}$ Department of Medical-Surgical Nursing, School of Nursing and Midwifery, Mashhad University of Medical Sciences, Mashhad, Iran

${ }^{2}$ Department of Medical Education, Faculty of Medicine, Mashhad University of Medical Sciences, Mashhad, Iran

$3,{ }^{*}$ Corresponding author: Student Research Committee, School of Nursing and Midwifery, Mashhad University of Medical Sciences, Mashhad, Iran. Email: sharifiph931@mums.ac.ir

${ }^{4}$ Student Research Committee, School of Nursing and Midwifery, Mashhad University of Medical Sciences, Mashhad, Iran

${ }^{5}$ Department of Medical-Surgical Nursing, School of Nursing and Midwifery, North Khorasan University of Medical Sciences, Bojnurd, Iran
} 
is noteworthy that this substantial shift requires the commitment of nursing authorities, as well as nursing instructors.

Now, a key question has been raised that deserves further attention: Why do nursing schools overlook the implementation of the nursing residency program for the training of senior nursing students?

This letter aimed to encourage the incorporation of the nursing residency program as a clinical course into the curriculum of senior nursing students. Our suggestions in this regard are that authorities and faculty members of nursing schools investigate the advantages and disadvantages of the nursing residency program for the clinical training of senior nursing students, evaluate the efficacy of this program in the preparation of students for their future role, identify the hindering factors in the transition process, and scrutinize the capability of this program to diminish the education-practice gap.

\section{References}

1. Wierzbinski-Cross H, Ward K, Baumann P. Nurses' perceptions of nurse residency: identifying barriers to implementation. J Nurses Prof Dev 2015; 31(1):15-20.

2. Friday L, Zoller JS, Hollerbach AD, Jones K, Knofczynski $\mathrm{G}$. The effects of a prelicensure extern program and nurse residency program on new graduate outcomes and retention. J Nurses Prof Dev 2015; 31(3):151-7.

3. Medas JC, Amato S, Grimm D, Radziewicz R, Rhodes C, VanHorn C, et al. Outcomes of a comprehensive nurse residency program. Nurs Manage 2015; 46(11):40-8.

4. Santos MC. Nurses' barriers to learning: an integrative review. J Nurses Staff Dev 2012; 28(4):182-5. 